\title{
Three Distinct Blue-Green Color Pathways in a Mammalian Retina
}

\author{
Stephen L. Mills, ${ }^{1}$ Lian-Ming Tian, ${ }^{1}$ Hideo Hoshi, ${ }^{1,2}$ Christopher M. Whitaker, ${ }^{1}$ and Stephen C. Massey ${ }^{1}$ \\ ${ }^{1}$ Department of Ophthalmology and Visual Science, University of Texas at Houston, Houston, Texas 77030, and ${ }^{2}$ Department of Anatomy, School of \\ Medicine, Toho University, Tokyo 143-8540, Japan
}

In mammalian retinae, the first steps in the process of discrimination of color are mediated by color-opponent neurons that respond with opposite polarity to signals from short (S, blue) and longer wavelength (M, green or L, red) cones. Primates also contain a second system that is different from $\mathrm{M}$ and $\mathrm{L}$ cones. Although pathways responding to the onset of S-cone stimulation (S-ON) are well known, the existence of bipolar cells and retinal ganglion cells that respond to the offset of S-cone stimulation (S-OFF) has been controversial. We have recorded from and stained three different types of S/M color-opponent ganglion cells in the rabbit retina that are distinguished by the polarity of their responses to $S$-cone stimulation, the stratification pattern of their dendrites, and the distinct mechanisms underlying their color-opponent responses. We describe an S-ON and an S-OFF pathway formed by amacrine cells inverting the S-ON signal. Most importantly, we also provide both anatomical and physiological evidence for a direct S-OFF pathway dependent on an S-OFF cone bipolar cell. The results indicate a greater diversity of pathways for processing of signals from S-cones than previously suspected.

Key words: color opponency; ganglion cell; retina

\section{Introduction}

Color vision is one of the most fundamental and salient perceptions, the neural underpinnings of which have been actively investigated from Wiesel and Hubel in 1966 to the present day. Primates are unique among placental mammals in possessing at least two independent chromatic systems that difference the outputs from spectrally tuned cones (Jacobs, 2009): the red-green or L/M and the blue-yellow or S/(M+L) systems, where $S, M$, and $L$ represent the short, medium, and long wavelength cones, respectively. Other mammals are similar to X-linked "color-blind" humans in possessing only two cone pigments: the S-cone and a longer wavelength cone; these animals use only an S/( $\mathrm{M}$ or L) system. These color systems are antagonistic, or color-opponent, in that the signals from neighboring cones are differenced, using lateral inhibition to reduce the overlap between the spectral regions. This inhibition increases the rate of change in the opponent systems as wavelength changes, thus increasing the ability to discriminate

Received Sept. 11, 2013; revised Nov. 25, 2013; accepted Dec. 20, 2013.

Author contributions: S.L.M. and H.H. designed research; S.L.M., L.-M.T., H.H., and C.M.W. performed research; S.L.M., C.M.W., and S.C.M. analyzed data; S.L.M. and S.C.M. wrote the paper.

This work was supported by the National Institutes of Health (Grant EY 06515 to S.C.M., Grant EY 10121 to S.L.M., Grant EY021958 to C.M.W., and Research to Prevent Blindness (Vision Core Grant EY10608, an unrestricted award to the Department of Ophthalmology and Visual Science, University of Texas at Houston Health Science (enter); and JSPS KAKENHI (Grant-in-Aid for Young Scientists B 30568382 to H.H.).

H. Hoshi's present address: Department of Anatomy, School of Medicine, Toho University, 5-21-16 Omori-Nishi, Ota-ku, Tokyo 143-8540, Japan.

The authors declare no competing financial interests.

Correspondence should be addressed to Stephen L. Mills, Department of Ophthalmology and Visual Science, University of Texas at Houston, 6431 Fannin, MSB 7.024, Houston, Texas 77030. E-mail: Stephen.L.Mills@uth.tmc.edu.

DOI:10.1523/JNEUROSCI.3901-13.2014

Copyright (C) 2014 the authors $\quad 0270-6474 / 14 / 341760-09 \$ 15.00 / 0$ small wavelength differences. How and at what retinal sites these opponent processes are generated remains controversial today.

The canonical circuit for color opponency consists of a receptive field center response generated by an $\mathrm{ON}$ or OFF type bipolar cell with selective S-cone or M-cone input and an antagonistic surround produced by feedback from horizontal cells to the cone photoreceptor terminals (Crook et al., 2009; Packer et al., 2010). Rabbit horizontal cells contact cones nonselectively (Hack and Peichl, 1999); therefore, the preponderance of $\mathrm{M}$-cones over $\mathrm{S}$-cones provides strong $\mathrm{M}$ antagonism of S-cones. However, an M-center/S-surround would be difficult to produce with $\mathrm{M}$-dominated horizontal cells and although OFF blue cone bipolar cells have been reported in primate and rabbit retinas (Klug et al., 2003; Liu and Chiao, 2007), this pathway has remained controversial and has yet to be demonstrated by physiological techniques. Two recent reports in ground squirrel retina were able to circumvent this difficulty by providing evidence for an $\mathrm{S}-/ \mathrm{M}+$ pathway derived via inversion of the canonical $\mathrm{S}+/ \mathrm{M}-$ signal by an intervening amacrine cell (Chen and Li, 2012; Sher and DeVries, 2012).

To obtain a clearer view of how S-cone signals are processed in the retina, we sought to determine the following: (1) the number of types of S/M ganglion cells in the rabbit retina, (2) whether S-OFF ganglion cells were present, and (3) how the response polarity and chromatic antagonism were established in any S-OFF types found. We learned to target and record from three different types of color-opponent ganglion cells, obtained their chromatic responses to visual stimuli, and determined their morphology by electroporation of neurobiotin. 

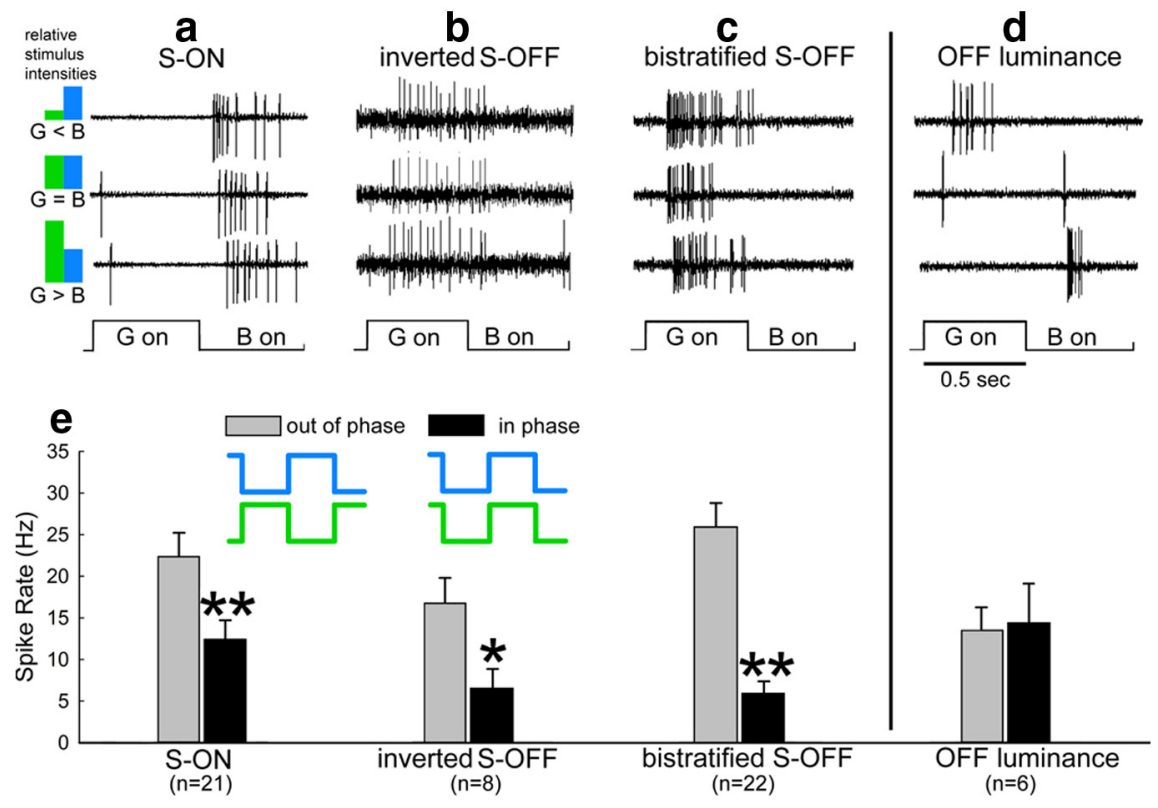

Figure 1. Ganglion cells were classified as color-opponent $(\boldsymbol{a}-\boldsymbol{c})$ or luminance cells $(\boldsymbol{d})$ by their responses to alternating flashes of a B-LED and a G-LED. The stimulus diagram (left) indicates the relative intensities for each row. The flash intensity of the B-LED was not varied and alternated with flashes of a G-LED the intensity of which was varied from much dimmer than the B-LED (top row) through equiluminant (middle row) to much brighter than the B-LED (bottom row). Three different types of S/M coloropponent ganglion cells consistently spike at the onset $(\boldsymbol{a})$ or the offset $(\boldsymbol{b}, \boldsymbol{c})$ of the B-LED regardless of the relative brightnesses of the LEDs. In contrast, an OFF luminance-sensitive ganglion cell ( $\boldsymbol{d}$ ) responds to offset of the brighter LED and has a minimal spiking response at equiluminance. $\boldsymbol{e}$, Responses were compared with B-LED and G-LED stimuli presented in phase or out of phase (diagram, center). For all three opponent cells, responses were smaller when the LEDs were on at the same time than when they were presented sequentially. OFF luminance cells responded slightly more when the LEDs were in phase. The B-LED and G-LED intensities in the in-phase conditions were isoluminant, as determined by the stimulus sequence shown in $\boldsymbol{a}-\boldsymbol{d}$, where the G-LED was varied from brighter to dimmer than the B-LED.

\section{Materials and Methods}

Tissue preparation, recording, and staining. Albino rabbits of either sex were anesthetized with urethane. The eyes were enucleated and the vitreous removed. All procedures were approved by the institutional Animal Welfare Committee. Pieces with sclera attached were mounted in a chamber and superfused with bicarbonate-buffered Ames medium bubbled with $95 \% \mathrm{O}_{2}+5 \% \mathrm{CO}_{2}$ and maintained at $32^{\circ} \mathrm{C}$. Somas were labeled by application of a drop of the nuclear stain acridine orange and recorded with loose-patch electrodes filled with Ames medium and 4\% neurobiotin. After recording, ganglion cell cells were stained by electroporation (Kanjhan and Vaney, 2008). Cells were selected from 3 to $8 \mathrm{~mm}$ ventral to the visual streak, avoiding the all S-cone region of the far ventral rabbit retina. With experience, ganglion cells could be targeted with enough efficiency to obtain numerous examples of each ganglion cell type based on the fluorescent intensity, size, and shape of the soma and nucleus.

Care was taken when acquiring cell recordings to minimize exposure of the retina to fluorescence. The cell was located and the electrode placed in position rapidly and then recordings were acquired without fluorescence. Visual stimulation and recordings began immediately, but recordings made in the first $10 \mathrm{~min}$ after acquisition were used to establish position and basic cell type and were not used in the data reported here. The major visual stimuli were always repeated and only recordings that stabilized were used. Although some differential bleaching may have occured initially, the stability of the recordings made normally over periods $>1$ h suggest that these effects do not persist long. We have been able to use this technique to record successfully from many types of ganglion cells (Hoshi et al., 2011, 2013), as have others (Dacey and Lee, 1994).

Bipolar cells were targeted using 4',6-diamidino-2-phenylindole (DAPI; Life Technologies) fluorescence (Mills and Massey, 1992) and stained via sharp-electrode iontophoresis of $4 \%$ neurobiotin $(0.5 \mathrm{nA}, 3$

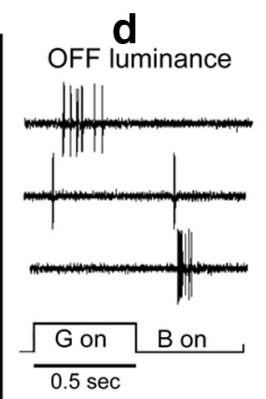

$\mathrm{Hz}, 1 \mathrm{~min})$. After $1 \mathrm{~h}$ of fixation in $4 \%$ paraformaldehyde, bipolar or ganglion cells were incubated overnight in 1:200 streptavidin-Cy3. Stratification was determined by obtaining $z$-rotations from $0.4 \mu \mathrm{m}$ optical sections using a Zeiss 510 Meta confocal microscope. Accurate depth measurements were enabled by comparison with the two fiducial bands provided by antibody staining of choline acetyltransferase (ChAT). L-AP4 and SR95531 (25 $\mu \mathrm{M}$; Tocris Bioscience) were used to block mGluR6 and $\mathrm{GABA}_{\mathrm{A}}$ receptors, whereas $20 \mathrm{~mm}$ HEPES and $3 \mu \mathrm{m}$ strychnine (Sigma-Aldrich) blocked horizontal cell feedback and glycine receptors. Effects of increased osmolarity of the added HEPES buffer were mimicked by substituting $20 \mathrm{~mm}$ sucrose (Sigma) without effect. Spiking was recorded and analyzed using Spike2 software (CED). Antibodies used were to ChAT (AB144p, goat, 1:500; Millipore), S-cone opsin (AB5407, rabbit, 1:400; Millipore), and GluR5 (SC7616, goat, 1:200; Santa Cruz Biotechnology). Immunostaining was performed in 3\% donkey serum and 1:200 secondary antibodies conjugated to Cy3, Cy5, Dylight-405 (Jackson Immunoresearch) or Alexa Fluor-488 (Life Technology).

Light stimulation. Blue (B) and green (G) LEDs provided full-field chromatic stimuli and were positioned $80 \mathrm{~mm}$ from the chamber. Cone-isolating stimuli were constructed by measuring the spectral composition of the LEDs and using the absorption spectra of rabbit M-cone and S-cones to balance the B-LED and G-LED outputs to produce stimulus transitions that strongly activated one cone type while leaving cone capture unchanged in the other cone type (Estévez and Spekreijse, 1982; Crook et al., 2009). Spectral intensities were measured with an ILT1700 radiometer (International Light Technologies). The LED signal was filtered with Newport band-pass filters at $10 \mathrm{~nm}$ intervals (with $11 \mathrm{~nm}$ half-bandwidths) from 400 to $640 \mathrm{~nm}$ to determine the spectral composition of the light emitted by the two LEDs. The B-LEDs and G-LEDs peaked at 430 and $520 \mathrm{~nm}$, with half bandwidths from 405 to $460 \mathrm{~nm}$ and 505 to $545 \mathrm{~nm}$, respectively. The LED intensities were measured when shining directly on the detector $\left(90^{\circ}\right)$ and adjusted by the following formula: $I=\sin (a)$, where $I$ is the intensity and $a$ the angle of incidence $\left(60^{\circ}\right.$ in our experiments). The intensities of the LEDs were determined by integrating across all wavelengths adjusted by the spectral distribution of the LEDs. The spectral distribution of the LEDs was multiplied by the rabbit cone spectral sensitivities (de Monasterio, 1978) to determine the $\mathrm{S}$-cone and $\mathrm{M}$-cone absorbances for each LED. The maximum B-LED and G-LED intensities used to stimulate the retina were 4.3 and $5.44 \mathrm{log}$ quanta $\mu \mathrm{m}^{-2} \mathrm{sec}^{-1}$, respectively.

For the S-cone-isolating stimulus, the B-LED was presented alone at $4.28 \log$ quanta $\mu \mathrm{m}^{-2} \mathrm{sec}^{-1}$ intensity, followed by the G-LED alone at $3.44 \log$ quanta $\mu \mathrm{m}^{-2} \mathrm{sec}^{-1}$. S-cone and M-cone captures were calculated for both stimulus phases. The G-LED intensity was chosen such that the $\mathrm{M}$-cone capture was equal in response to the B-LED or G-LED stimuli. Our calculations indicate that the transition between the two phases of the S-cone-isolating stimulus produced 91\% color contrast for $\mathrm{S}$-cones and $0 \%$ for the G-cones. M-cone contrast was therefore silenced at transitions between these B-LED and G-LED settings.

For the G-cone-isolating stimulus, the G-LED was presented alone at $5.44 \log$ quanta $\mu \mathrm{m}^{-2} \mathrm{sec}^{-1}$ intensity, followed by the B-LED alone at $4.95 \log$ quanta $\mu \mathrm{m}^{-2} \mathrm{sec}^{-1}$. S-cone and $\mathrm{M}$-cone captures were again calculated for both stimulus phases. Here, the transition between the two phases of the M-cone-isolating stimulus produced $91 \%$ color contrast for $\mathrm{M}$-cones and $0 \%$ for S-cones. 


\section{S-ON}

$(n=22)$

a

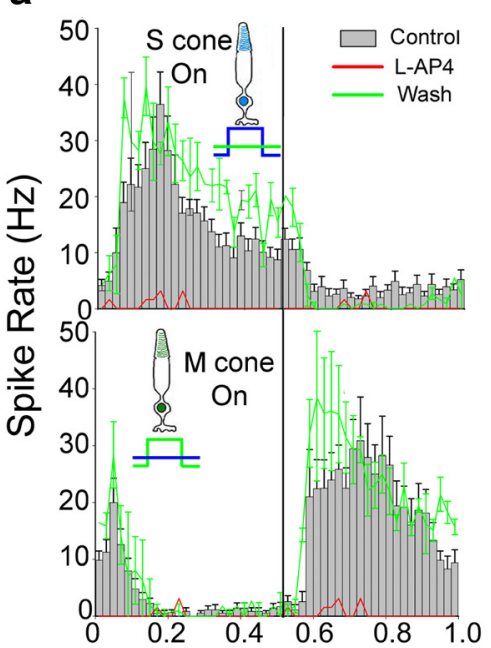

inverted S-OFF

$(n=8)$

$\mathrm{S}$ or $\mathrm{M}$ cone isolating stimuli bistratified S-OFF

$(n=20)$
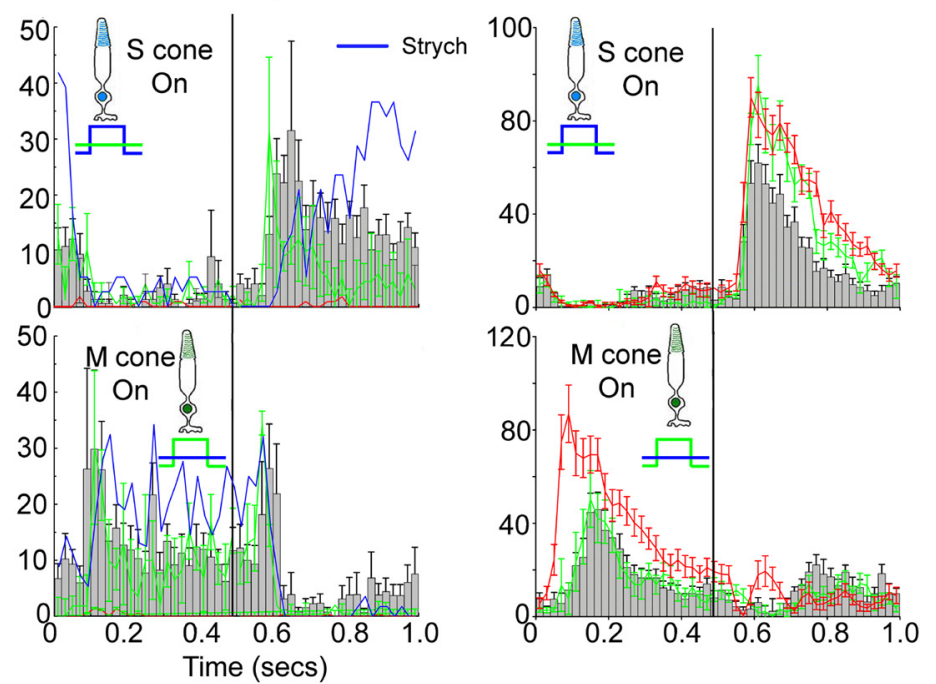

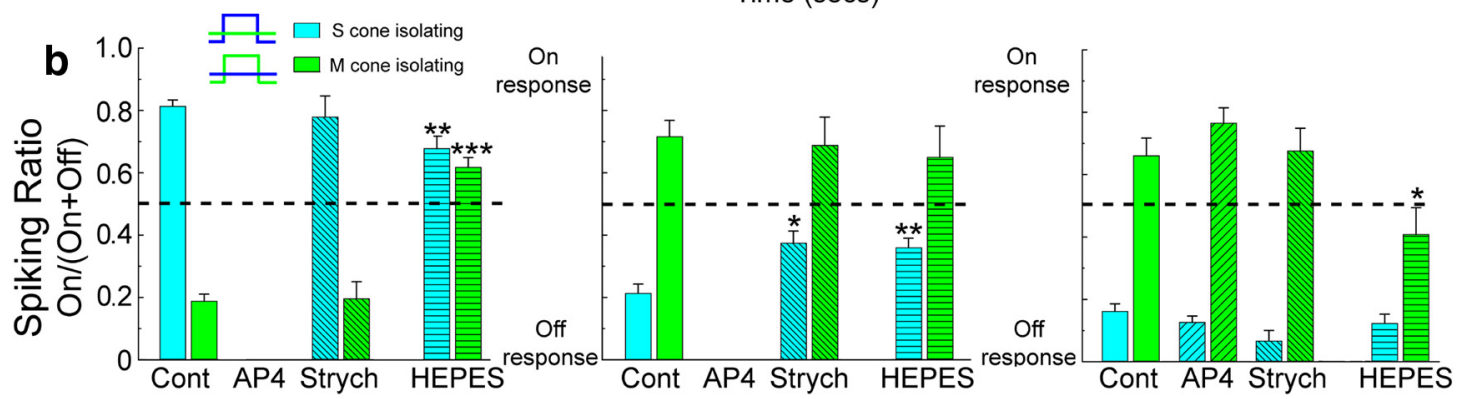

Figure 2. The three types of $\mathrm{S} / \mathrm{M}$ opponent ganglion cells have different response properties when cone-isolating stimuli were used to stimulate $\mathrm{S}$-cones or M-cones in isolation. The diagrams of cone-isolating stimuli represent relative cone capture for the S-cones and M-cones, where there is high contrast for one cone type and low contrast for the other type. Vertical lines separate responses to the onset phase of each isolating stimulus from the responses to the offset phase. $\boldsymbol{a}$, Poststimulus time histograms for control and red (L-AP4) and green (washout of L-AP4) traces represent the mean spike rate $\pm 1 \mathrm{SE}$ (where shown) for all cells tested for the cell type and drug condition portrayed. Strychnine data (blue lines) is shown for only the inverted S-OFF ganglion cell. The S-ON ganglion cell (left) spikes at the onset of S-cone stimulation (top) or the offset of M-cone stimulation (bottom). The two S-OFF ganglion cells (center, right) had the opposite polarity. L-AP4 (red traces) reversibly abolished spiking in the S-ON and inverted S-OFF cells, but not the bistratified S-OFF cell. $\boldsymbol{b}, 0 \mathrm{~N}$ or OFF polarity was quantified for S- or M-cone-isolating stimuli by dividing spiking in the onset phase by total spiking. Antagonistic polarities were seen for all three cell types. L-AP4 did not alter opponency in the bistratified S-OFF type. Strychnine (Strych) did not significantly alter opponency except in the inverted S-OFF type, where the $S$-cone offset response was blocked. HEPES buffer reduced horizontal cell-mediated antagonism from M-cones in both the S-ON $\left(t_{(34)}=\right.$ $11.45, p<0.001)$ and bistratified S-0FF ganglion cells $\left(t_{(35)}=3.465, p<0.05\right)$ and reduced the selectivity for OFF stimuli in the inverted S-0FF ganglion cell $\left(t_{(9)}=2.66, p<0.05\right)$. It also reduced the $\mathrm{ON}$ polarity of the $\mathrm{S}$-cone-isolated response for $\mathrm{S}$ - $\mathrm{ON}$ ganglion cells $\left(t_{(33)}=3.413, p<0.01\right)$. All comparisons are between controls (Cont) and drug treatments.

Because the light was projected at an angle, photoreceptor screening may lower the nominal intensity, which should be considered a maximal value. Due to these uncertainties, photoisomerization rates are not reported. The stimuli were cone isolating for the stimulus intensities we report. Differential screening of the light from the B-LEDs versus G-LEDs might occur, but the physiological results suggest that the difference in contrasts remained high.

Other chromatic stimuli consisted of B- or G-flashes of increasing intensity or B-flashes of constant intensity alternated with G-flashes the brightness of which was varied from much lower to much higher than the B-LED.

Validation of S-cones. Staining with an antibody to GluR5 allows identification of the location and sizes of cone pedicles, although the staining is actually just below the cone pedicles in the dendrites of OFF cone bipolar cells. GluR5-staining at the pedicles of M-cones is both brighter and larger than that at S-cones. The positions of the cone pedicles in the area containing the S-OFF cone bipolar cells were delineated with antiGluR5 and the size and intensity information collected for each cell (ImageJ). Optical sections were $0.4 \mu \mathrm{m}$ in the $z$-axis. GluR5 staining from six other patches near the first injected S-OFF bipolar cell were also examined to provide a comparison with a large sample size. GluR5 intensity and volume measurements were analyzed used the clustering routine mclust from R (University of Washington Statistics Department), with two clear clusters emerging. The outer segments of S-cones were labeled with anti-S-cone opsin. Pedicles apposed to small, dim GluR5 structures were invariably proximal to an immunostained S-cone outer segment. GluR5 staining from a second S-OFF bipolar cell was clustered separately because it was taken from an eccentricity with different cell sizes and spacing.

\section{Results}

We were able to regularly target, record from, and label three distinct types of S/M opponent ganglion cells in the rabbit retina. One type ( $\mathrm{S}-\mathrm{ON} ; n=23$ ) was excited by increased absorption in $\mathrm{S}$-cones and/or decreased absorption in M-cones. In addition to this ON ganglion cell, we also recorded from two types of S-OFF ganglion cells, which were distinguishable by their dendritic stratification, response characteristics, and responses to pharmacological agents. Spiking activity in the S-ON and a second type, the inverted S-OFF cell $(n=8)$, were abolished by L-AP4, which blocks ON bipolar cell responses at the mGluR6 receptor. This confirms a recent report of an $\mathrm{S}-/ \mathrm{M}+$ ganglion cell in ground squirrel formed by an inversion of the $S+/ M-$ pathway by an 
intermediary amacrine cell; spiking in this squirrel $\mathrm{S}-/ \mathrm{M}+$ ganglion cell was also blocked by L-AP4 (Chen and Li, 2012; Sher and DeVries, 2012). We call this cell the "inverted S-OFF" because the polarity is the inversion of the S-ON bipolar cell. We also identified a third and novel type of S/M ganglion cell in the rabbit retina, a bistratified S-OFF cell $(n=22)$. This cell continued to spike in the presence of L-AP4 and antagonists of inhibitory neurotransmitters, indicating that its S-OFF signal cannot derive from $\mathrm{ON}$ pathways and is not critically dependent on amacrine cell inputs.

\section{All three types of ganglion cells are color opponent}

Evidence that these three types of ganglion cells encode chromatic contrast instead of luminance is shown in Figure 1, in which the stimulus consisted of alternating flashes from B-LEDs and G- LEDs. The intensity of the B-LED was held constant, whereas that of the G-LED was altered in a sequence from much dimmer than the B-LED to much brighter (see the stimulus sequence diagram in Fig. 1, left). The spike rate in ganglion cells that primarily encode luminance contrast (Fig. 1, right) reaches a minimum when the relative brightnesses are equal and spiking is maximal in the phase containing the brighter stimulus for $\mathrm{ON}$ luminance cells or the dimmer stimulus for OFF luminance cells. In contrast, all three $\mathrm{S} / \mathrm{M}$ cell types (Fig. 1 $a-c$ ) showed consistent signaling of the chromatic $\mathrm{B} / \mathrm{G}$ signal regardless of the relative brightness of the two LEDs; that is, they always spiked synchronously with the B-LED even if it was much dimmer than the G-LED. The average latency of the inverted S-OFF to $S$ stimuli was $113 \pm 12.8 \mathrm{~ms}$ (mean $\pm 1 \mathrm{SE}$ ) compared with $78 \pm 7.1$ and $89 \pm 5.0 \mathrm{~ms}$ for the S-ON and bistratified S-OFF types, suggesting a longer neural pathway for the inverted S-OFF type. The firing of all three types was sustained throughout the period of stimulation with the preferred stimulus.

Color opponent cells combine an OFF response to one hue with an ON response to another hue; for example, S-ON and M-OFF (Crook et al., 2009; Yin et al., 2009). Responses are maximal when the opponent hues are presented out of phase, so that the ON response to one hue will combine with the OFF response to the other hue. Destructive interference occurs when the two hues are presented in phase. Figure le shows that response is maximal in all three cell types when the B-LED and the G-LED are presented sequentially and that spiking was significantly reduced when when the two LEDs are illuminated at the same time, again indicating the presence of color opponency (S-ON: $t=$ $2.705, p=0.01$; inverted S-OFF $t=2.689, p=0.0176$; bistratified $\mathrm{S}$-OFF, $t=6.323, p<0.001)$. There was no interference seen with a group of OFF luminance cells receiving the same stimuli.

Color opponency in these chromatic cells was further tested with stimuli that strongly varied photon capture in one cone class while keeping photon capture equal in the other (see Materials and Methods). All data in Figure 2 was obtained with cone-isolating stimuli, where S-cone capture was modulated while M-cone capture was kept constant (Fig. 2, top) or where M-cone capture was modulated while S-cone capture was kept constant (Fig. 2, bottom). The onset phase of each stimulus, where cone capture is highest, is marked with a blue (Fig. 2, top) or green (Fig. 2, bottom) cone. Mean poststimulus time histograms are shown for the control data and the mean responses for L-AP4 (Fig. 2, red lines) and washout (Fig. 2, green lines) data are shown as lines. The response to strychnine is shown for the inverted S-OFF cells (Fig. 2, blue lines). Errors bars are omitted in the strychnine data for clarity; in the phase containing the most activity, the average SE was $\sim 5.4 \mathrm{~Hz}$ for both S- and M-isolating stimuli. Strychnine data are also not shown for S-ON and bistratified
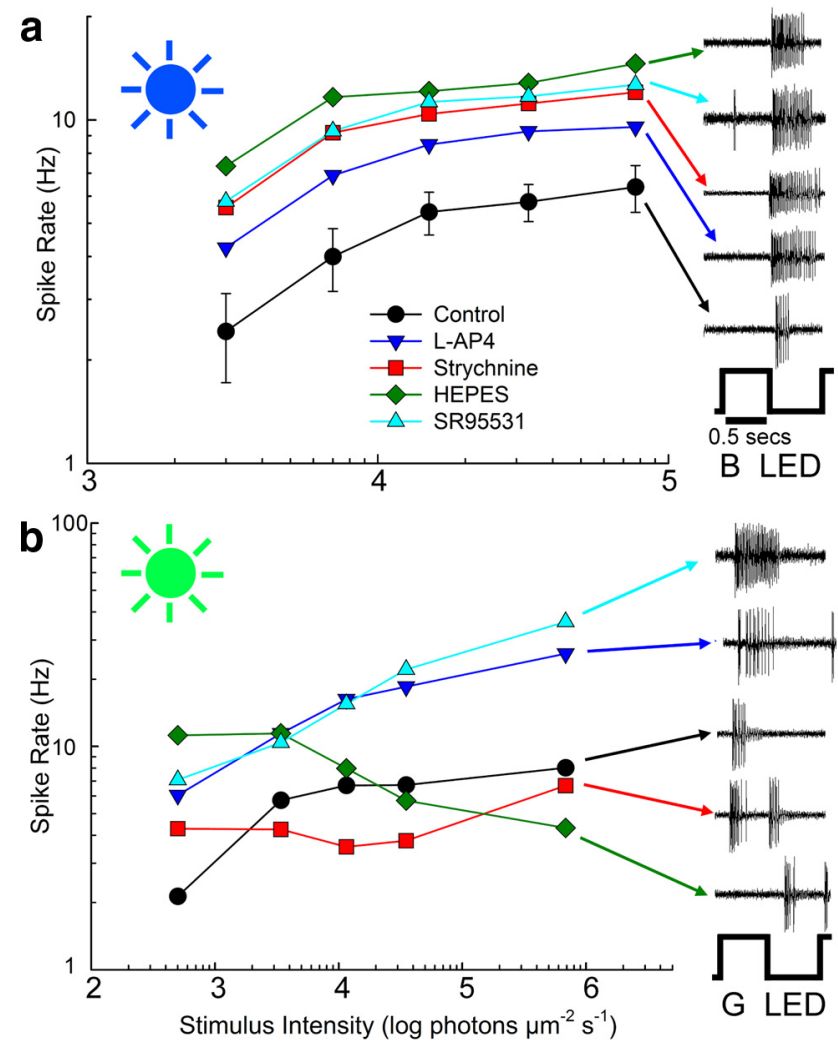

Figure 3. $a$, The responses of bistratified S-OFF ganglion cells to flashes of the B-LED alone were almost exclusively OFF responses at all intensities of the LED. Blocking inhibition in amacrine cell or horizontal cells did not affect the shape of the intensity-response function, but only increased firing rate. $\boldsymbol{b}$, The responses of bistratified S-OFF ganglion cells to flashes of the G-LED were almost exclusively ON responses in control, L-AP4, and SR95531 conditions. Strikingly, HEPES buffer produced a shift to OFF response, indicating a block of the antagonistic $\mathrm{M}+$ response produced by horizontal cell feedback.

S-OFF conditions because its effects were largely disinhibitory in these cells, increasing spiking in bistratified S-OFF cells by almost $50 \%$ and making the S-ON cell more sustained. Comparison of the response to S-isolating stimuli (Fig. 2a, top) and M-isolating stimuli (Fig. $2 a$, bottom) revealed the color opponency of each cell type, where spiking in a ganglion cell was driven by increased activity in one cone class or decreased activity in the other. In the S-ON ganglion cell, the cone-isolating stimuli produced spiking when S-cone stimulation was increased or M-cone stimulation was decreased (Fig. 2a, left). Conversely, spiking was elicited in inverted S-OFF and bistratified S-OFF ganglion cells by decreases in S-cone absorption or increases in M-cone absorption (Fig. 2a, center, right). Application of L-AP4 (25 $\mu \mathrm{M}$; (Fig. 2, red lines) reversibly abolished responses in S-ON and inverted S-OFF ganglion cells, whereas spiking persisted in bistratified S-OFF ganglion cells, indicating direct $\mathrm{S}$-cone input from S-OFF bipolar cells. The overall increase in spiking in bistratified S-OFF ganglion cells in the presence of L-AP4 is common in cells in the OFF pathway due to the loss of inhibition from amacrine cells, the excitatory drive of which depends on ON bipolar cells (Arkin and Miller, 1987; Werblin, 2010).

Conversely, Figure $2 a$, bottom, shows responses to M-coneisolating stimuli. For each cell type, the polarity of the response is reversed. Increased M-cone activity produced an OFF response in S-ON ganglion cells, but an ON response in inverted and bistratified S-OFF ganglion cells. Together with the S-cone-isolating data shown in Figure $2 a$, top, it is clear that chromatic opponency is found in each of the three cell types. 

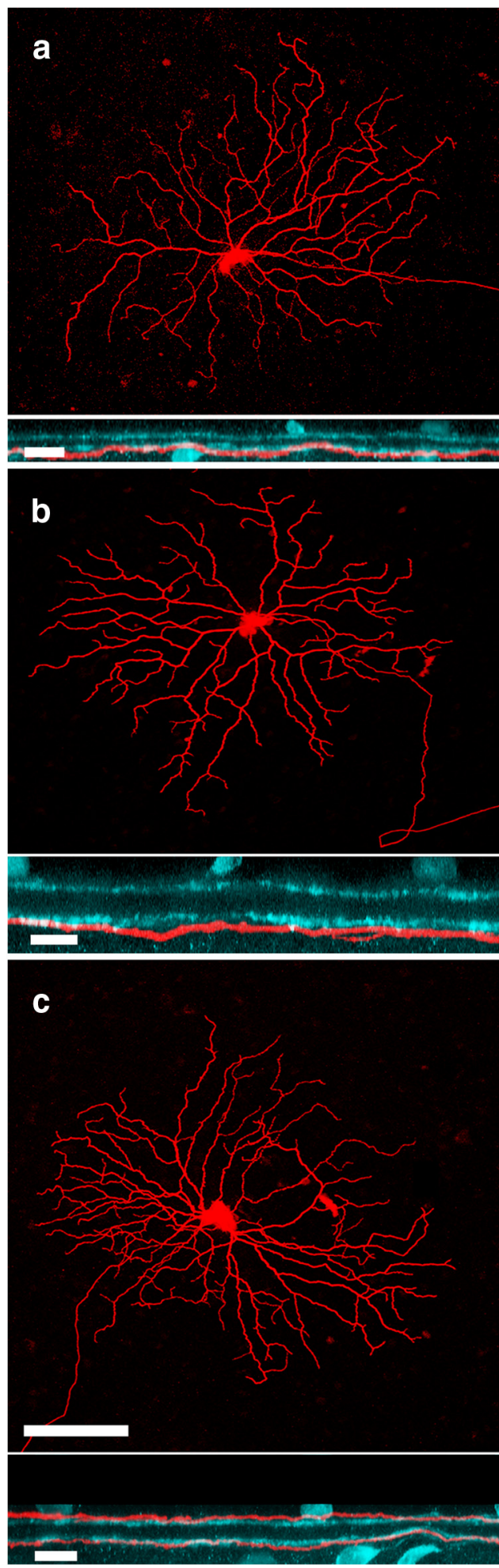

Figure 4. The morphology and stratification of the three types of $S / M$ opponent ganglion cells. TheS-ON (a) and inverted S-OFF ganglion cells $(\boldsymbol{b})$ each ramify at $\sim 75 \%$ depth in the inner plexiform layer (IPL) and have similar morphologies. c, The bistratified S-OFF ganglion cell with direct OFF blue cone bipolar cell input ramifies at $\sim 14 \%$ and $77 \%$ depth in the IPL, where $0-40 \%$ represents sublamina a (OFF bipolar cells) and the remainder is sublamina b (ON bipolar cells). Red, Neurobiotinstaining; cyan, ChAT immunostaining. Scale bar, $100 \mu \mathrm{m} ; z$-projections $=10 \mu \mathrm{m}$.

Figure $2 b$ shows the quantified response polarity elicited by these $\mathrm{S}$ - and $\mathrm{M}$ - cone-isolating stimuli. Response polarity (ON vs $\mathrm{OFF}$ ) was calculated by dividing the spike rate in the onset phase for the cone-isolating stimuli, where photon capture is highest, by total spiking in both phases. This ratio distinguishes between strong ON activity (near 1), strong OFF (near 0 ), or absence of color-opponency (0.5). Color opponency, where the responses to $\mathrm{M}$-cone and S-cone stimulation show opposite polarity, was seen in all three cell types (Fig. $2 a, b$ ) in response to the S-coneisolating stimuli (blue histograms) and $\mathrm{M}$-cone-isolating stimuli (green histograms).

\section{Mechanisms of color opponency}

Changes in the strength or polarity of opponency after drug treatments made it possible to investigate the underlying mechanisms. The influence of amacrine cell inputs was examined with the glycine receptor antagonist strychnine and the $\mathrm{GABA}_{\mathrm{A}}$ antagonist SR95531. HEPES buffer, which has been shown to reduce the effects of horizontal cell feedback (Hirasawa and Kaneko, 2003; Davenport et al., 2008; Packer et al., 2010), was used to examine the role of horizontal cells. In S-ON ganglion cells, strychnine increased spiking but did not alter the relative contributions of the $\mathrm{S}+$ or $\mathrm{M}-$ responses (Fig. $2 b$, left). HEPES (20 mM) abolished opponency through reduction of $\mathrm{M}$-dominated horizontal cell feedback to S-cones, blocking the offset response produced by G-light (Fig. 2b, left). This resulted in relative indifference of $\mathrm{S}-\mathrm{ON}$ ganglion cells to the M-cone-isolating stimulus-spiking was relatively equal in the ON and OFF phases. SR95531 increased firing rates, but did not by itself alter the color opponency in any cell type and is not shown. Therefore, the S-ON ganglion cell obtains color opponency via $\mathrm{M}$-cone-dominated horizontal cell feedback and not from amacrine cells.

The inverted S-OFF ganglion cell is distinguished by its OFF polarity to the onset of blue light, but its response is blocked by L-AP4. Sher and DeVries (2012) found that strychnine also blocked color opponency in their S-OFF type by blocking the response to offset of the B-isolating stimulus. In inverted S-OFF ganglion cells in the rabbit, spiking was also abolished at offset of the S-cone-isolating stimulus; however, the results were more variable and complex (Fig. $2 a$, upper middle, blue line). Each inverted S-OFF ganglion cell showed an initial suppression of firing at S-cone offset in response to $3 \mu \mathrm{M}$ strychnine, but resumed spiking at latencies of up to $300 \mathrm{~ms}$. When the period of the stimulus cycle was increased from 1.0 to $3.0 \mathrm{~s}$, this initial suppression in response to $\mathrm{S}$-cone-isolating stimulus lengthened to $>700 \mathrm{~ms}$. In addition, responses to the M-cone-isolating stimulus were unchanged at either duration except for an overall increase in sustained firing (Fig. $2 a$, lower middle, blue line). This difference from the ground squirrel study may be due to differences in the stimulus configuration. We used full-field LED stimulation, whereas the ground squirrel study used white noise stimuli of relatively high spatial frequency (Sher and DeVries, 2012). Because it is difficult to see how blocking glycinergic input would dramatically delay firing, we speculate that the resumption of spiking is due to a repolarization process in these cells. The disorganized and gradual resumption of spiking suggests a gradual recovery from inhibition rather than the onset of a synchronous excitatory process. Determining the nature of this effect will require further investigation. In both the ground squirrel and rabbit inverted S-OFF ganglion cell, however, synchronous spiking upon offset of S-cone stimulation is blocked by strychnine.

HEPES altered color opponency in inverted S-OFF cells by reducing spiking in the offset phase of the S-cone stimulus (Fig. $2 b$, center, blue). We observed that spiking to the S-OFF stimulus was strongly depressed by HEPES in all inverted S-OFF cells, whereas the responses to both S-ON and M-ON stimuli were enhanced. Because HEPES decreases horizontal cell feedback to 

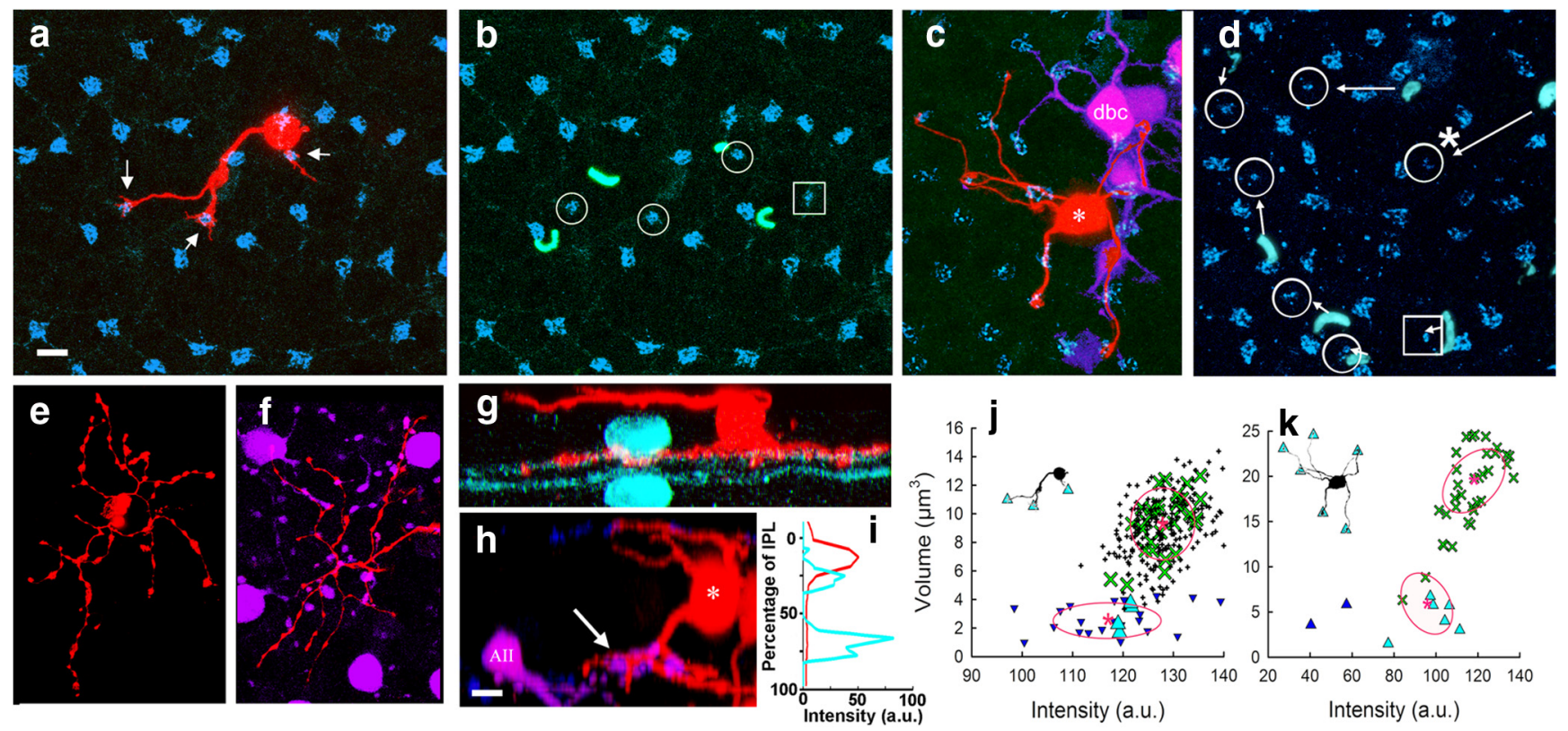

Figure 5. Two S-OFF blue cone bipolar cells. $\boldsymbol{a}$, The dendrites (arrows) of a bipolar cell (red) injected with neurobiotin contacts three cone pedicles (blue; stained with anti-GluR5) while avoiding others in the area. $\boldsymbol{b}$, Four of the cone pedicles can be distinguished as less brightly stained and smaller than the others. These include the three contacted by the bipolar cell (circles) and one that is not (square). The outer segments of S-cones stained with anti-S-cone opsin (cyan) proximal to the four designated pedicles identifies them as S-cones. $c$, The dendrites of a second bipolar cell (*) contact six $S$-cone pedicles. A nearby All amacrine cell was also injected with neurobiotin, resulting in staining of nearby All amacrine cells and depolaring ON cone bipolar cells, one of which (dbc) is seen near the S-selective bipolar cell. These were pseudocolored magenta for contrast. $\boldsymbol{d}$, The position of the six putative S-cone pedicles (circles) and an another not contacted by the bipolar cell (square) are shown. The relative positions of the outer segments (cyan) is more variable at this eccentricity. Arrows mark the closest outer segment to each S-cone pedicle, including S-cones outside of the field. The one exception (*) occurred when the rightmost outer segment lacked an S-cone pedicle near it and the nearer S outer segment was matched to a pedicle to its left. $\boldsymbol{e}, \boldsymbol{f}$, The axon-terminals of the S-0FF bipolar cells in $\boldsymbol{a}$ and $\boldsymbol{c}$, respectively. The somas and lobular appendages of an All amacrine cell are shown in magenta. Note that the dendrites of the bipolar cell costratify with the lobular appendages of the All amacrine cell, which ramify in sublamina a. $\boldsymbol{g}, \boldsymbol{h}, \boldsymbol{z}$-rotations of the bipolar cells in $\boldsymbol{a}$ and $\boldsymbol{c}$ (red) shows that they ramify in sublamina a of the inner plexiform layer. Staining with an antibody to ChAT (cyan) labels starburst amacrine cells as a fiducial marker in $\boldsymbol{g}$; the lobular appendages (arrow) of the All amacrine cell (All, magenta) serve as a marker in $\boldsymbol{h}$. $\boldsymbol{i}$, Stratification in $\boldsymbol{g}$ was quantified by placing a line profile across the micrograph. The red line shows the stratification depth of the bipolar cell axon terminal at $\sim 17 \%$ depth and the cyan line shows the ChAT staining.j, Scatterplot of cone pedicle size and staining intensity after GluR5-staining shows two distinct populations of cone pedicles. S-cones are reliably smaller and dimmer than the M-cones. The red plus signs and ellipses represent the centroids and 1 SD derived from a cluster analysis of 272 GluR5-labled puncta from 7 images; the 3 cones contacted by the bipolar cell had membership probabilities of $1,0.99$, and 0.97 in the smaller cluster, which were verified as the $S$-cone population both by relative proportion (10\%) and the presence of nearby stained $S$-cone opsin outer segments. Cones seen in $\boldsymbol{a}$ are shown as cyan upward triangles ( $\mathrm{S}$-cones) and green X's (M-cones). Cone pedicles from the larger sample are shown as small downward triangles (S-cones) or pluses (M-cones). $\boldsymbol{k}$, Similar scatterplot from the second bipolar cell injection. Brightness and size of these pedicles differed from those in $\boldsymbol{j}$, which was from dorsal retina. These were analyzed and clustered separately. The six pedicles contacted by the second bipolar cell had membership probabilities in the smaller putative S-cone cluster ranging from 0.98 to 1.0. Scale bars: $\boldsymbol{a}-\boldsymbol{f}, 10 \mu \mathrm{m} ; \boldsymbol{g}, \boldsymbol{h}, 5 \mu \mathrm{m}$.

cone pedicles, the release of glutamate from both S-cones and $\mathrm{M}$-cones would increase. This would result in increased depolarization of the S-ON cone bipolar cell upon activation of S-cones; the subsequent increase in depolarization of the postsynaptic glycinergic amacrine cell would result in increased hyperpolarization of the inverted S-OFF ganglion cell, suppressing firing in the OFF phase, thereby moving its spiking ratio closer to 0.5 (indifference).

The antagonistic response in the inverted S-OFF class is mediated by direct, excitatory input by $\mathrm{M}$-cone-dominated $\mathrm{ON}$ bipolar cells. The M-ON signal in this class is not affected by HEPES, which indicates that any color opponency derived from horizontal cells is overshadowed by the direct $\mathrm{M}-\mathrm{ON}$ input. Although the S-OFF responses of these cells are at least partially blocked by strychnine, this had no effect on the amplitude of the $\mathrm{M}-\mathrm{ON}$ responses. This finding suggests that the surround responses of the S-ON bipolar cells is primarily produced by $\mathrm{M}-\mathrm{ON}$ bipolar cell input rather than being conveyed to the monostratified S-OFF cell via glycinergic amacrine cells.

\section{S-OFF signal in bistratified S-OFF ganglion cells must derive from an S-OFF bipolar cell}

In bistratified S-OFF cells, spiking persisted in the presence of L-AP4, which is consistent with it receiving excitatory input from an OFF S-cone bipolar cell (Fig. 2a,b; right). The failure of glycine or $\mathrm{GABA}_{\mathrm{A}}$ antagonists to block the S-OFF signal rules out an inversion of the S-ON signal. HEPES reduced color opponency by changing the $\mathrm{M}-\mathrm{ON}$ response to M-OFF (Fig. $2 b$, green, right), suggesting that, as in the S-ON cells, color opponency is generated by horizontal cell feedback onto S-cones.

Examination of the responses to flashes of increasing intensity of each color of LED are also consistent with the bistratified S-OFF ganglion cell receiving excitatory input from an OFF $\mathrm{S}$-cone bipolar cell. The average response of the bistratified $\mathrm{S}$-OFF cells to the B-LED was dominated by the S-OFF response (Fig. 3a), which increased with increasing B-LED intensity. Application of the drugs L-AP4, strychnine, SR95531, and HEPES all increased responses by a constant factor, indicating again that the excitatory response was determined by an S-OFF bipolar cell and that the drugs acted to increase the gain of that mechanism by a constant amount related to block of inhibition from various pathways. Similarly, individual spike traces from a representative cell show B-OFF responses regardless of drug condition (Fig. $3 a$, right).

\section{M-ON signal in bistratified S-OFF ganglion cells arises from inhibitory mechanisms}

The response to flashes of increasing intensity of the G-LED was more complex, because different mechanisms of inhibition were called into play. Figure $3 b$ shows the differences in spiking as the 
intensity of the G-LED was increased. Spiking in the M-ON phase increased with G-LED intensity in the presence of L-AP4 or SR95531, indicating the dominance of M-ON mechanisms. Spiking decreased with intensity in the HEPES condition, as spiking shifted from a coloropponent M-ON mechansims to M-OFF (Fig. $3 b$, spike traces, green). Responses in the presence of strychnine remained predominantly ON, although ON-OFF responses were seen in some cells at some intensities (Fig. 3b, spiking insets).

The M-ON signal in inverted S-OFF ganglion cells derive in large part from excitatory input from $\mathrm{M}$-dominated $\mathrm{ON}$ bipolar cells (see Mechanisms of color opponency, above; Sher and DeVries, 2012). This is not true for S-OFF bistratified ganglion cells, because L-AP4, which would block M-ON bipolar cell inputs, increased $\mathrm{M}-\mathrm{ON}$ antagonism well beyond control (Fig. 3b).

\section{Cell morphologies}

Staining revealed a consistent morphology for each of the three physiological ganglion cell types. The dendrites of S-ON (Fig. $4 a$ ) and inverted S-OFF (Fig. 4b) types both ramified at an $\sim 75 \%$ depth in the inner plexiform layer below the lower cholinergic band (Famiglietti, 2008) and were also similar in morphology. The bistratified S-OFF type (Fig. 4c) sent processes to both $\mathrm{ON}$ and OFF layers, ramifying $\sim 14 \%$ and $~ 77 \%$ depth in the inner nuclear layer (INL), where $0 \%$ and $100 \%$ denote the borders the inner plexiform layer makes with the INL and ganglion cell layers, respectively. This makes the bistratified S-OFF distinct from the other two types.

While plausible candidates for depolarizing (ON) blue cone bipolar cells have been found in numerous species (Kouyama and Marshak, 1992; Li and DeVries, 2006), hyperpolarizing (OFF) blue cone bipolar cells have seldom been found, leading many to doubt their existence. A bipolar cell type has been described previously in rabbit retina, the dendrites of which appear to selectively contact S-cones and which ramifies in sublamina a (Liu and Chiao, 2007). By targeting bipolar cells stained with DAPI (Mills and Massey, 1992; Liu and Chiao, 2007), we also stained cone bipolar cells $(n=2)$ that selectively contacted S-cones (Fig. $5 a-$ $d, j, k)$ and ramified in the OFF layer at the same depth as the outer dendrites of the bistratified S-OFF type (Fig. $5 g-i$ ). Our two examples support the existence of an S-OFF bipolar cell, as proposed by Liu and Chiao, 2007), in that our cells not only ramify in the OFF sublamina at the same depth as the distal dendrites of the bistratified S-OFF ganglion cell (Fig. 4), but also at the same depth (5-15\%), as reported by Liu and Chao (2007).

These OFF bipolar cells selectively contact S-cones. An antibody to S-opsin was used to stain the outer segments of S-cones (Fig. $5 b, d$ ), whereas an antibody to GluR5 was used to stain the basal area around S-cone and M-cone pedicles (Fig. $5 a-d$ ). Scatterplots of cone pedicle size and staining intensity after GluR5staining (Fig. 5j,k) revealed two distinct populations of cone pedicles. GluR5-staining adjacent to S-cone pedicles was reliably smaller and dimmer than that belonging to M-cones. Based on the clustering parameters, the three cones contacted by the first bipolar cell had membership probabilities of 1.0,0.99, and 0.97 in the smaller cluster, which was verified as the S-cone population both by relative proportion of the total cones (10\%) and by the presence of nearby stained S-cone opsin outer segments (Fig. 5b).

The second S-OFF bipolar cell contacted six cones and the calculated membership probabilities in the smaller (S-cone) cluster ranged from 0.98 to 1.0. The size of the GluR5 staining of the putative $S$-cones in this second example was visually distinctive in size, being considerably smaller than the putative M-cones. However, the displacement from the stained outer segments was larger and more variable in this material (Fig. $5 d$ ).

This second S-OFF bipolar cell was stained in material also contained nearby AII amacrine cells stained with neurobiotin, resulting in numerous AII amacrine cell somas and processes in the near vicinity, as well as some dye-coupled ON cone bipolar cells (Fig. $5 c, f, h$ ). This allows the lobular appendages of AII amacrine cells, which lie entirely in sublamina a, to serve as a fiducial marker. The axon terminal of the S-OFF cone bipolar cell costratify with these lobules, indicating their position in the OFF sublamina (Fig. $5 f, h$ ). The axon terminals of the two S-OFF bipolar cells are similar in branching pattern and depth (Fig. 5e,f).

\section{Discussion}

A complete understanding of color opponency has been seriously hampered by the difficulty in encountering such cells due to their low spatial density and to the limited number of studies in which there were morphological identification of the types (Yin et al., 2009; Dacey et al., 2013). Therefore, our recordings with labeling of three different types of B/G color-opponent ganglion cells and investigation of the mechanisms involved provide important new data. Whereas the number and type of S/M opponent cells encountered by blind recordings was restricted to one or two types, 
it now appears that there are at least three S/M ganglion cell types in both rabbit and primate retina (Dacey and Packer, 2003; Dacey et al., 2013). We also found that color opponency can arise from three different mechanisms, including via horizontal cell feedback, from combinations of cone bipolar cells of opposite polarity and cone selectivity, or from amacrine cell inputs (Fig. 6). The combination of physiology, surround mechanisms, and morphology reliably separates these three cell classes.

\section{Morphology of S/M ganglion cells}

The only prior staining of an S/M ganglion cell after physiological characterization from a dichromatic retina was in guinea pig retina (Yin et al., 2009), in which both $\mathrm{S}+/ \mathrm{M}+$ and $\mathrm{S}-/ \mathrm{M}+$ ganglion cells were represented. Both of these types ramified in the ON layer, as reported here for the S-ON and inverted S-OFF ganglion cells, and they suggested their $\mathrm{S}-/ \mathrm{M}+$ was inverted from the S-ON bipolar cell as reported here and in the ground squirrel studies (Chen and Li, 2012; Sher and DeVries, 2012). The $\mathrm{S}$-ON ganglion cell appears to be the same as a type stained by the Golgi technique, the dendrites of which made extensive contacts with axon terminals of an S-ON bipolar cell, also Golgi stained (Famiglietti, 2008).

The S-OFF-bistratified ganglion cell type we described $(n=$ 22) does not appear to have been described previously in rabbit retina (Roska et al., 2006; Rockhill et al., 2002). A cell with similar stratification was found in guinea pig retina (Yin et al., 2009). One of these investigators' two recordings of this type showed strong S-cone sensitivity, but responded with S-ON polarity and both cells were overall nonopponent. In the rabbit bistratified $\mathrm{S}$-OFF ganglion cell, the strength of the $\mathrm{S}-/ \mathrm{M}+$ color contrast always increased with blockade of the ON pathway with L-AP4. This could be traced to an increase in the $\mathrm{M}+$ signal in the L-AP4 data, suggesting that the $\mathrm{M}+$ signal does not originate from $\mathrm{M}$-dominated ON bipolar cell input onto the $\mathrm{ON}$ dendrites of the bistratified S-OFF ganglion cell. Instead, it is the surround signal of the S-OFF bipolar cell, generated by horizontal cell feedback and therefore blocked by HEPES, similar to the $\mathrm{S}+/(\mathrm{L}+\mathrm{M})-$ (small bistratified) ganglion cell in primates (Crook et al., 2009).

\section{Two types of S-OFF ganglion cell in the rabbit retina}

The results with the inverted S-OFF S- $-\mathrm{M}+$ ganglion cell confirm previous reports that amacrine cells generate S-OFF responses in other mammalian retinas. The existence of this pathway has been proposed previously as an explanation for the increased latency of S-OFF ganglion cells (Hemmi et al., 2002; Li and DeVries, 2006; Sher and DeVries, 2012), a result that we also observed. As in the ground squirrel studies, $\mathrm{M}+$ opponency appears to be primarily derived from direct input onto the ganglion cell by M-ON bipolar cells. In the case of the ground squirrel (Chen and Li, 2012; Sher and DeVries, 2012), the bipolar cell may be selective for M-cones (Light et al., 2012). In the rabbit retina, no M-cone-selective bipolar cells have yet been identified (Mills and Massey, 1992), but the relative M-dominance formed by nonselective bipolar cell/cone contacts would be sufficient to form M-dominated bipolar cell signals in the nonselective types.

The existence of S-OFF ganglion cells excited by S-OFF bipolar cells is controversial due to the complete lack of physiological evidence and also because anatomical evidence for S-OFF bipolar cells has been sparse. Suitable candidates for S-OFF bipolar cells have not been reported in catalogs of rat, mouse, and ground squirrel (Euler and Wässle, 1995; Ghosh et al., 2004; Light et al., 2012). However, previous positive reports include a sparse, coneselective OFF bipolar cell stained via the Golgi technique in hu- mans (Kolb et al., 1992) and the S-cone-selective bipolar cells that ramify in the OFF sublamina previously reported in rabbit retina (Liu and Chiao, 2007). Also in rabbit, a Golgi-stained OFF bipolar cell ("wa") with sparse dendrites that make selective contacts with cones and have axonal arbors with the same morphology and stratification pattern as the S-cone-selective bipolar cells labeled in this study and Liu and Chiao (2007) was reported by Famiglietti (2008). Finally, an S-OFF midget bipolar cell described in ultrastructure in primate (Klug et al., 2003) could potentially support S-OFF signaling in the central retina, where single cone contacts occur, but presumably would not constitute an independent S-OFF type. We have now confirmed the previous report in rabbit with two additional examples of bipolar cells with S-cone-selective contacts made by their dendrites and axons that ramify at the same depth as the distal dendrites of bistratified S-OFF ganglion cells and as the putative S-OFF bipolar cells of Liu and Chaio (2007). Although the total number of these putative S-OFF bipolar cells remains low at $n=4$ across the two studies, the four injected bipolar cells appear to be morphologically similar and thus suggest that the substrate for the physiological responses reported here may also exist in rabbit.

The S-OFF-bistratified cell surprisingly ramifies in both the $\mathrm{ON}$ and OFF sublaminae. The purpose of the dendrites in sublamina $b$ is not clear, because L-AP4 does not reduce excitatory input. There are precedents for stratification without bipolar cell inputs, however. The ON-bistratified ganglion cell (Roska et al., 2006; Hoshi et al., 2013) does not receive OFF bipolar cell input on its processes in sublamina a, whereas the uniformity detector ramifies in both ON and OFF layers, apparently without bipolar cell input in either layer (Sivyer and Vaney, 2010).

The results with bistratified S-OFF cell in this study provide the first physiological evidence for a controversial OFF S-cone pathway arising directly from an OFF S-cone bipolar cell. This signal cannot derive from an ON S pathway, because it is not blocked by L-AP4, or from an inversion via an interneuron, because it is not blocked by antagonists of GABA or glycine. The signal must, therefore, originate from an S-OFF cone bipolar such as that previously proposed (Liu and Chiao, 2007) and supported here.

\section{References}

Arkin MS, Miller RF (1987) Subtle actions of 2-amino-4-phosphonobutyrate (APB) on the Off pathway in the mudpuppy retina. Brain Res 426:142-148. CrossRef Medline

Chen S, Li W (2012) A color-coding amacrine cell may provide a blue-off signal in a mammalian retina. Nat Neurosci 15:954-956. CrossRef Medline

Crook JD, Davenport CM, Peterson BB, Packer OS, Detwiler PB, Dacey DM (2009) Parallel ON and OFF cone bipolar inputs establish spatially coextensive receptive field structure of blue-yellow ganglion cells in primate retina. J Neurosci 29:8372-8387. CrossRef Medline

Dacey DM, Lee BB (1994) The 'blue-on' opponent pathway in primate retina originates from a distinct bistratified ganglion cell type. Nature 367: 731-735. CrossRef Medline

Dacey DM, Packer OS (2003) Colour coding in the primate retina: diverse cell types and cone-specific circuitry. Curr Opin Neurobiol 13:421-427. CrossRef Medline

Dacey DM, Crook JD, Packer OS (2013) Distinct synaptic mechanisms create parallel S-ON and S-OFF color opponent pathways in the primate retina. Vis Neurosci, in press. CrossRef Medline

Davenport CM, Detwiler PB, Dacey DM (2008) Effects of $\mathrm{pH}$ buffering on horizontal and ganglion cell light responses in primate retina: evidence for the proton hypothesis of surround formation. J Neurosci 28:456-464. CrossRef Medline

De Monasterio FM (1978) Spectral interactions in horizontal and ganglion cells of the isolated and arterially-perfused rabbit retina. Brain Res 150: 239-258. CrossRef Medline 
Estévez O, Spekreijse H (1982) The "silent substitution" method in visual research. Vision Res 22:681-691. CrossRef Medline

Euler T, Wässle H (1995) Immunocytochemical identification of cone bipolar cells in the rat retina. J Comp Neurol 361:461-478. CrossRef Medline

Famiglietti EV (2008) Wide-field cone bipolar cells and the blue-ON pathway to color-coded ganglion cells in rabbit retina. Vis Neurosci 25:53-66. CrossRef Medline

Ghosh KK, Bujan S, Haverkamp S, Feigenspan A, Wässle H (2004) Types of bipolar cells in the mouse retina. J Comp Neurol 469:70-82. CrossRef Medline

Hack I, Peichl L (1999) Horizontal cells of the rabbit retina are nonselectively connected to the cones. Eur J Neurosci 11:2261-2274. CrossRef Medline

Hemmi JM, James A, Taylor WR (2002) Color opponent retinal ganglion cells in the tammar wallaby retina. J Vis 2:608-617. Medline

Hirasawa H, Kaneko A (2003) pH changes in the invaginating synaptic cleft mediate feedback from horizontal cells to cone photoreceptors by modulating $\mathrm{Ca}^{2+}$ channels. J Gen Physiol 122:657-671. CrossRef Medline

Hoshi H, Tian LM, Massey SC, Mills SL (2011) Two distinct types of ON directionally selective ganglion cells in the rabbit retina. J Comp Neurol 519:2509-2521. CrossRef Medline

Hoshi H, Tian LM, Massey SC, Mills SL (2013) Properties of the ON bistratified ganglion cell in the rabbit retina. J Comp Neurol 521:1497-1509. CrossRef Medline

Jacobs GH (2009) Evolution of colour vision in mammals. Philos Trans R Soc Lond B Biol Sci 364:2957-2967. CrossRef Medline

Kanjhan R, Vaney DI (2008) Semi-loose seal Neurobiotin electroporation for combined structural and functional analysis of neurons. Pflugers Arch 457:561-568. CrossRef Medline

Klug K, Herr S, Ngo IT, Sterling P, Schein S (2003) Macaque retina contains an S-cone OFF midget pathway. J Neurosci 23:9881-9887. Medline

Kolb H, Linberg KA, Fisher SK (1992) Neurons of the human retina: a Golgi study. J Comp Neurol 318:147-187. CrossRef Medline

Kouyama N, Marshak DW (1992) Bipolar cells specific for blue cones in the macaque retina. J Neurosci 12:1233-1252. Medline
Li W, DeVries SH (2006) Bipolar cell pathways for color and luminance vision in a dichromatic mammalian retina. Nat Neurosci 9:669-675. CrossRef Medline

Light AC, Zhu Y, Shi J, Saszik S, Lindstrom S, Davidson L, Li X, Chiodo VA, Hauswirth WW, Li W, DeVries SH (2012) Organizational motifs for ground squirrel cone bipolar cells. J Comp Neurol 520:2864-2887. CrossRef Medline

Liu PC, Chiao CC (2007) Morphologic identification of the OFF-type blue cone bipolar cell in the rabbit retina. Invest Ophthalmol Vis Sci 48:3388 3395. CrossRef Medline

Mills SL, Massey SC (1992) Morphology of bipolar cells labeled by DAPI in the rabbit retina. J Comp Neurol 321:133-149. CrossRef Medline

Packer OS, Verweij J, Li PH, Schnapf JL, Dacey DM (2010) Blue-yellow opponency in primate S-cone photoreceptors. J Neurosci 30:568-572. CrossRef Medline

Rockhill RL, Daly FJ, MacNeil MA, Brown SP, Masland RH (2002) The diversity of ganglion cells in a mammalian retina. J Neurosci 22:38313843. Medline

Roska B, Molnar A, Werblin FS (2006) Parallel processing in retinal ganglion cells: how integration of space-time patterns of excitation and inhibition form the spiking output. J Neurophysiol 95:3810-3822. CrossRef Medline

Sher A, DeVries SH (2012) A non-canonical pathway for mammalian bluegreen color vision. Nat Neurosci 15:952-953. CrossRef Medline

Sivyer B, Vaney DI (2010) Dendritic morphology and tracer-coupling pattern of physiologically identified transient uniformity detector ganglion cells in rabbit retina. Vis Neurosci 27:159-170. CrossRef Medline

Werblin FS (2010) Six different roles for crossover inhibition in the retina: correcting the nonlinearities of synaptic transmission. Vis Neurosci 27: 1-8. CrossRef Medline

Wiesel TN, Hubel DH (1966) Spatial and chromatic interactions in the lateral geniculate body of the rhesus monkey. J Neurophysiol 29:1115-1156. Medline

Yin L, Smith RG, Sterling P, Brainard DH (2009) Physiology and morphology of color-opponent ganglion cells in a retina expressing a dual gradient of S and M opsins. J Neurosci 29:2706-2724. CrossRef Medline 